\title{
Effect of Carbon Black on Characteristics of a Selected EPDM-Based Thermal Insulator Composite
}

\author{
Mahmood E.Mohamed ${ }^{*}$, Sahar El-Marsafy ${ }^{\dagger}$, Saeed Hasanin ${ }^{\ddagger}$, Tamer Z. Wafy ${ }^{\S}$
}

\begin{abstract}
Ethylene-propylene-diene terpolymer (EPDM) based thermal insulator represent efficient class of the high temperature thermal insulators due to their excellent thermal, mechanical and ablative properties. This classed insulator is often reinforced by Kevlar pulp and fumed silica. Ammonium Sulphate and antimony trioxide mixture as a flame retardant was added. Carbon black (CB) was added to enhance the elastomer ablative properties. different concentrations of $\mathrm{CB}$ were investigated. In this work, the effect of carbon black content on the characteristics of a selected EPDM based insulating formulation has been investigated. The tensile strength, hardness and elongation have been slightly improved. The thermal stability via thermal gravimetric analysis (TGA-DTG) and differential scanning calorimetry (DSC) also has been slightly improved. Whereas the ablation resistance has been considerably improved. the weight loss from sample containing $10 \mathrm{phr}$ decreased by $28 \%$ relative to the neat specimen.
\end{abstract}

Keywords: Heat shielding materials, Ablatives, EPDM, Thermal characterization, Oxyacetylene torch test

\section{Introduction}

To fabricate and design an elastomeric thermal insulator for solid rocket motors (SRM), the insulating layer is located between the solid propellant and the motor chamber. This elastomeric layer has two important functions. Firstly, it absorbs the mechanical stresses induced to the rocket motor during the propellant casting, storage, and flight [1]; Secondly, it protects the motor case from high temperature gases and particles generated by the propellant combustion, as passive cooling system[2][1]. Also, it protects the structures, the aerodynamic surfaces and the payload of vehicles and rockets during ultrasonic flight through the atmosphere. To be clear, the structural case of a SRM, which serves as a pressure vessel for the combustion gases, must be protected against high temperature (above $2800{ }^{\circ} \mathrm{C}$ ) and pressures (about 60 bar) [1][3].

Ablative materials play a strategic role in the aerospace and some military industries. Ablation is an erosive phenomenon with a removal of material by a combination of thermo-mechanical and thermo-chemical factors from high temperature, pressure, and velocity of combustion flame in SRM

Egyptian Armed Forces, Egypt; ma7mood.3emad@gmail.com

Cairo University, Egypt.

Egyptian Armed Forces, Egypt; s.hasanien@mtc.edu.eg

Egyptian Armed Forces, Egypt; tamer.z.wafy@mtc.edu.eg 
Ethylene-propylene diene terpolymer (EPDM) rubber is a terpolymer of ethylene, propylene, and a non-conjugated diene. EPDM exhibits outstanding resistance to oxidation, weathering effects, and excellent low temperature properties[4]. EPDM also has the lowest density among elastomer $\left(\sim 0.85 \mathrm{~g} / \mathrm{cm}^{3}\right)[5]$. It has thermal conductivity and glass transition temperature of about $0.25 \mathrm{~W} / \mathrm{m} / \mathrm{K}$ and $-50 \mathrm{C}$ [4], respectively, which can introduce it as a suitable heat insulator binder. Long shelf life and excellent low temperature properties are also two important properties of EPDM. Meanwhile, the char yield and ablation resistance of EPDM is relatively low that need to be reinforced with fillers.

Among the various types of polymeric matrices used in ablatives, the burnt matrix is relatively weak [6], even when using a high char retention material. To improve the char retention phenomena, different types of reinforcements can be added to the matrix. Fibers made of carbon, mineral asbestos or glass are typically used. Micron-sized powdered fillers also play a very important role. However, several limitations associated with the traditional ablative composites, which are structured on a micron scale [7][8]. In fact, even in the presence of fibrous reinforcements, the material can suffer high mechanical erosion. On the other hand, after approaching Nano-sized reinforcements it was an obvious improvement of reinforcing of the matrix. Composite materials produced with Nano sized reinforcements have led to a new level of ablation resistance[9][10][11].

Carbon black and silica, including fumed and precipitated silica, are two main fillers to improve mechanical and ablative properties of the elastomeric insulators[12]. Fumed silica such as Aerosil shows a higher reinforcing effect and higher ablation resistance in comparison with the precipitated silica because it has finer particle size and a higher specific surface area. In comparison with the precipitated silica, lower density and thermal conductivity can be obtained with the fumed silica[13]. So, fumed silica can play very important role in reinforcing the matrix with low density and improving the thermal resistivity as well.

Although not so long ago, asbestos was the best reinforcement for solid rocket insulation due to outstanding performance in mechanical, thermal and ablative; however, asbestos has been discarded because of its environmental pollution[14][15][16]. Therefore, the thermal properties have not been evaluated in the industrial and operational tests. Furthermore, Kevlar and carbon fiber- reinforced insulators do not have the ablative performance comparable with the asbestos-reinforced insulators. To improve the ablative performance, fibrous fillers have been used with the other fillers such as flame retardant or char former[17].

In the recent years, ammonium polyphosphate has also been used as char former and flame retardant to decrease spreading rate of the flame[1]. Also, ammonium sulfate and antimony oxide are used as a hybrid flame retardant[18][2]. The hybrid flame retardant blocks the surface of the matrix when forming a carbonized layer in the flame side.

\section{Materials and Methods}

A low viscosity semi-crystalline grade ethylene-propylene-diene rubber (DuPont, Dutral TER-4049), locally supplied by El-kammash, Egypt supplier of Versalis Italy, was used as a matrix. Aramid pulp (Twaron 1099, supplied by Teijin).

Fumed Nano silica grade (Aldrich), was used to increase the ablation resistance of the material: according to our experience and to the wide literature previously reported on EPDM based Elastomeric Thermal Insulators, $15 \mathrm{phr}$ of Nano silica resulted to be a proper amount of silica able to produce good ablative properties[18][19][20]. Paraffin oil (BFR 20, supplied by Alfa-Egypt) was used as a plasticizer: the use of oils reduces the mixing energy and time also 
improving the preservation of the fibrous reinforcements[19][21]. A crystalline dicumyl peroxide (Sigma Aldrich) was chosen as vulcanizing agent. The EPDM were prepared using a double rolls calendar. First, the raw EPDM was added to the calendars at room temperature. The Nano silica was then added; the flame retardant and Nano silica was added. Applying 10 minutes of mixing then Kevlar fiber and oil were added. finally, the peroxide added with 30 minutes of continuous mixing.

Table 1 reports the exact formulations of all compositions. The composite materials containing carbon black N990 with different weights. The compounds were vulcanized at 180 ${ }^{\circ} \mathrm{C}$ for 10 minutes in a heated press at a pressure of 50 bar, producing two types of sheets: one with a thickness of $2 \mathrm{~mm}$ and the second one with a thickness of $15 \mathrm{~mm}$ [19]. From the first type of sheet, dog bones specimens for the mechanical analysis and cylindrical specimens (50 $\mathrm{mm}$ diameter) used for the oxyacetylene-torch test.

Table 1 Compositions of the different formulations.

\begin{tabular}{l|cccccc} 
& NEAT & C 0.5 & C 1 & C 2 & C 5 & C 10 \\
\hline EPDM (Phr) & 100 & 100 & 100 & 100 & 100 & 100 \\
Peroxide (Phr) & 5 & 5 & 5 & 5 & 5 & 5 \\
Paraffin oil (Phr) & 4 & 4 & 4 & 4 & 4 & 4 \\
Ammonium Sulphate (Phr) & 35 & 35 & 35 & 35 & 35 & 35 \\
$\mathrm{Sb}_{\mathbf{2}} \mathrm{O}_{\mathbf{3}}$ (Phr) & 10 & 10 & 10 & 10 & 10 & 10 \\
Kevlar pulp (Phr) & 4 & 4 & 4 & 4 & 4 & 4 \\
Fumed Silica (Phr) & 15 & 15 & 15 & 15 & 15 & 15 \\
Carbon Black N990 (Phr) & - & 0.5 & 1 & 2 & 5 & 10
\end{tabular}

The thermal stability of the composites was evaluated by using a Thermogravimetric Analyzer (TGA) Q500, and consisted in dynamic scans at a heating rate of $20{ }^{\circ} \mathrm{C} / \mathrm{min}$ with Ramp method. The samples were tested in nitrogen with a flow rate of $20 \mathrm{~mL} / \mathrm{min}$ from room temperature up to $1000{ }^{\circ} \mathrm{C}$. Bulk samples of about (1-2) mg were used[1].

The calorimetric measurements were done using a Perkin-Elmer differential scanning calorimeter (DSC) in a dry nitrogen atmosphere with a flow rate of $20 \mathrm{~mL} / \mathrm{min}$. The sample weight was (2-4) mg. Dynamic differential scanning calorimetry (DSC) analysis was performed in the temperature range of -70 to $400^{\circ} \mathrm{C}$ at heating rate $5^{\circ} \mathrm{C} / \mathrm{min}$.

The testing of ablative materials requires the use of hyper thermal environment with very high heat fluxes, conditions which cannot be produced by TG analysis, both in terms of the elevated heating rate (up to $50,000{ }^{\circ} \mathrm{C} / \mathrm{min}$ ) and due to the impossibility to simulate any shear stress caused by combustion gases. In this work, an oxy-acetylene torch was used to simulate the severe hyper thermal environment: this test setup is able to produce both high temperatures (up to $3000{ }^{\circ} \mathrm{C}$ ) [22] and high heat fluxes (up to $900 \mathrm{~W} / \mathrm{cm}^{2}$ ) [16][1]. Many researches on ablatives have been successfully carried out using this setup: a more detailed description of this device can be found in Natali et al[16]. The test kit is constructed mainly from a steel sheet $300 \mathrm{~mm} \times 300 \mathrm{~mm} \times 6 \mathrm{~mm}$ with a horizontal wooden base with dimensions $400 \times 300 \times 8 \mathrm{~mm}$. A high temperature, sensitive digital thermocouple k-type is attached to the steel sheet with high-temperature grade liner. The thermocouple can read temperature of the insulated side up to $1200{ }^{\circ} \mathrm{C}$ precisely.

In this test, the distance between the sample surface and the flame was set at $10 \mathrm{~mm}$ and the heat flux produced by the torch was set at $500 \mathrm{~W} / \mathrm{cm}^{2}$. An acetylene on oxidizer ratio equal to 1.33 was selected in order to produce a neutral flame: this condition allows to minimize the 
thermo-oxidative ablation of the tested material to satisfy the ASTM E-285-80 [19][22][23]. The temperature profile was acquired at the steel sheet back-face. All the samples were exposed to the flame for $40 \mathrm{~s}$ [19]. The loss of weight due to the ablation process was also calculated.

\section{Results and Discussion}

Carbon black samples were set in a comparison with each other and the neat sample in the following:

\section{a. TGA}

The TG (weight loss curves) and DTG (derivative weight loss) patterns of the compositions are showed in Fig.1 and Fig.3 respectively.

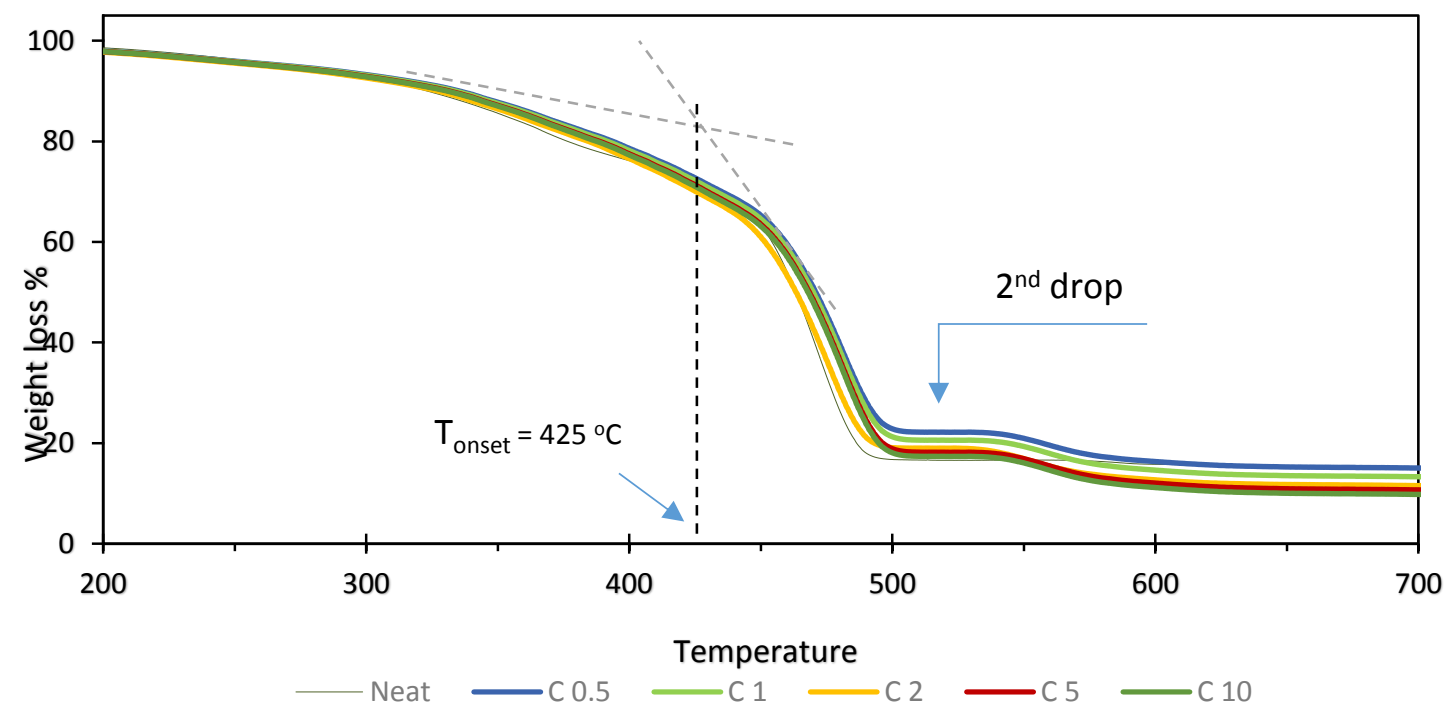

Figure 1 TG patterns of the produced elastomeric heat shielding materials in nitrogen.

The TG results nearly have the same degradation pattern. The residue percentage differs slightly and illustrated in table 2 at final temperature $890{ }^{\circ} \mathrm{C}$. Onset temperatures of the samples are nearly the same $\mathrm{T}_{\text {onset }}=425^{\circ} \mathrm{C}$. In CB samples, there is a slight drop in the weight loss curve at $550{ }^{\circ} \mathrm{C}$ in Fig.2, this drop refers to carbon black oxidation and vaporizing as gaseous oxides. As a proof of this explanation, it is notable that neat curve has not dropped at $550{ }^{\circ} \mathrm{C}$. Despite the nitrogen environment, the decomposition of polymer raises oxides and oxygen until $500{ }^{\circ} \mathrm{C}$. At $550{ }^{\circ} \mathrm{C}$, the polymer is completely decomposed. At $550-600{ }^{\circ} \mathrm{C}$ the carbon black decomposed by oxidation. [24] 


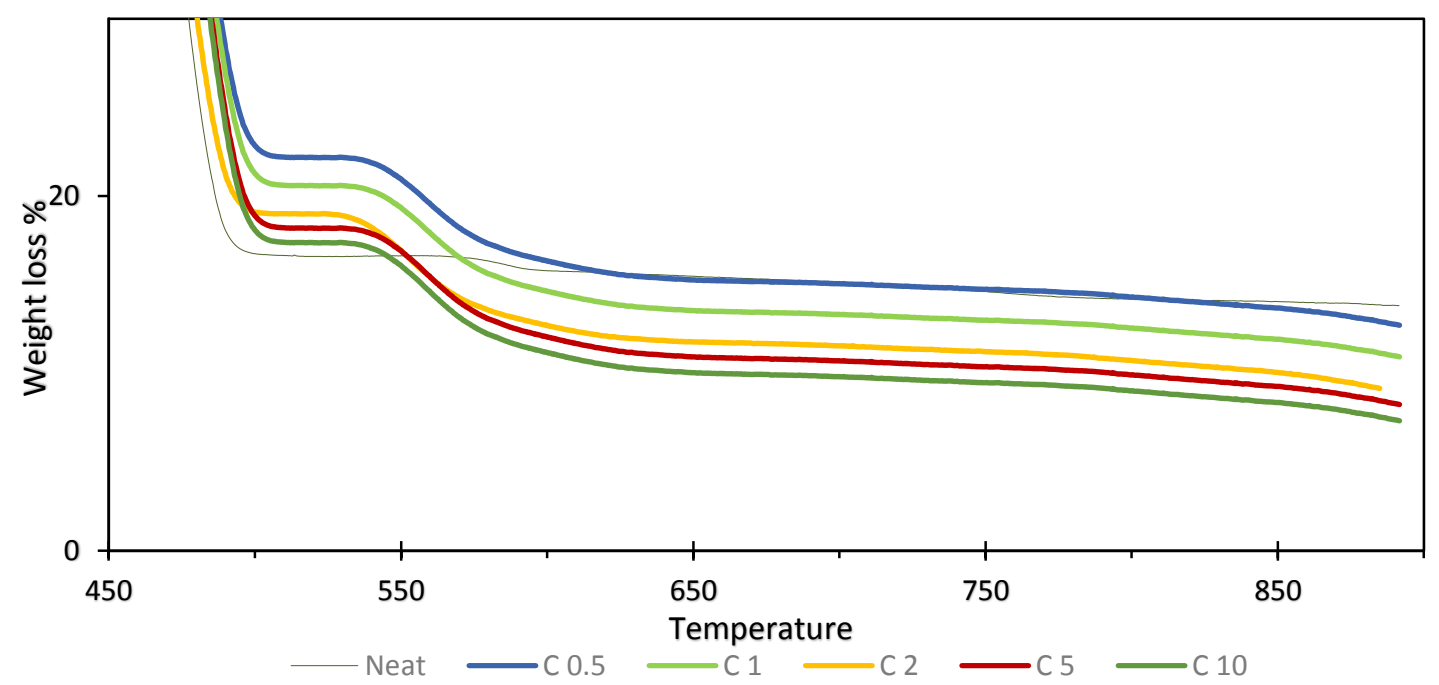

Figure 2 Magnified TG patterns at specific range of temperature

By increasing the carbon black content, the residue percentage decreased: which means carbon atoms combines with oxygen from the binder forming carbon dioxide.

Table 2 Residues percentage after TG analysis at $890{ }^{\circ} \mathrm{C}$

\begin{tabular}{lllllll}
\hline composition & Neat & C 0.5 & C 1 & C 2 & C 5 & C 10 \\
\hline Residue \% & 13.82 & 12.72 & 10.93 & 9.158 & 8.24 & 7.33
\end{tabular}

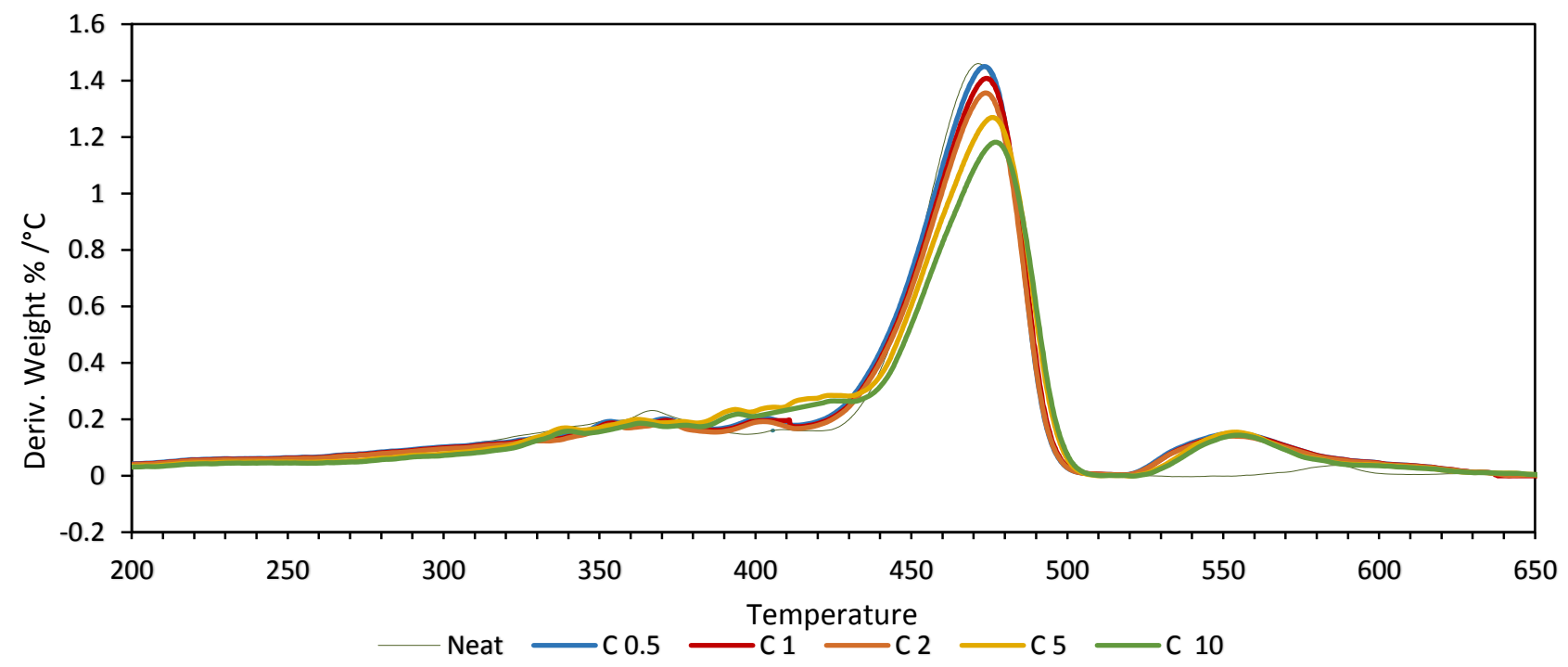

Figure 3 DTG patterns of the produced elastomeric heat shielding materials in nitrogen

The DTG curves showing increasing the temperature of the maximum degradation. The shifting right of the peak means more thermal stability. Also, the peak of DTG analysis decreased by increasing carbon content. The second minimal peak in carbon samples only, represent the carbon black oxidation. By increasing the temperature, peroxide decomposed $(\mathrm{ROH})$ and release oxygen. This oxygen atom tends to form more stable compound $\left(\mathrm{CO}_{2}\right)$ and oxidize carbon black. Table 3 states the peak values of the DTG curve to maintain the effect of CB clearly. 
Table 3 Peak values of DTG analysis

\begin{tabular}{l|cccccc} 
& NEAT & C 0.5 & C 1 & C 2 & C 5 & C 10 \\
\hline Temperature & 471.35 & 473.36 & 473.85 & 473.75 & 475.87 & 477.37 \\
Deriv. Weight & 1.46 & 1.449 & 1.407 & 1.35 & 1.269 & 1.181
\end{tabular}

\section{b. Thermomechanical Analysis}

Samples TMA patterns shown in Fig. 4 tested Up to a temperature of approximately $470{ }^{\circ} \mathrm{C}$, all the elastomers ae exhibited an expansion mainly related to the elastomeric matrix. Above this temperature, pyrolysis gases were produced and the degradation of the matrix was coupled with increasing of the volume due to the bubbles then shrinkage occurs.

Among all the samples, C10 sample showed the smaller change. The most probable reason was that the increased carbon black content increases the capability of holding the residues of the degraded material.

Thermal expansion coefficient (CTE) of the samples was calculated in Fig.5. The figure shows more stability in dimensions change of $\mathrm{C} 10$ then stability decreased till neat sample. Low CTE is very important in thermal insulation of space industry to avoid shrinkage or shape diffusion of the insulation layer and heat leakage.

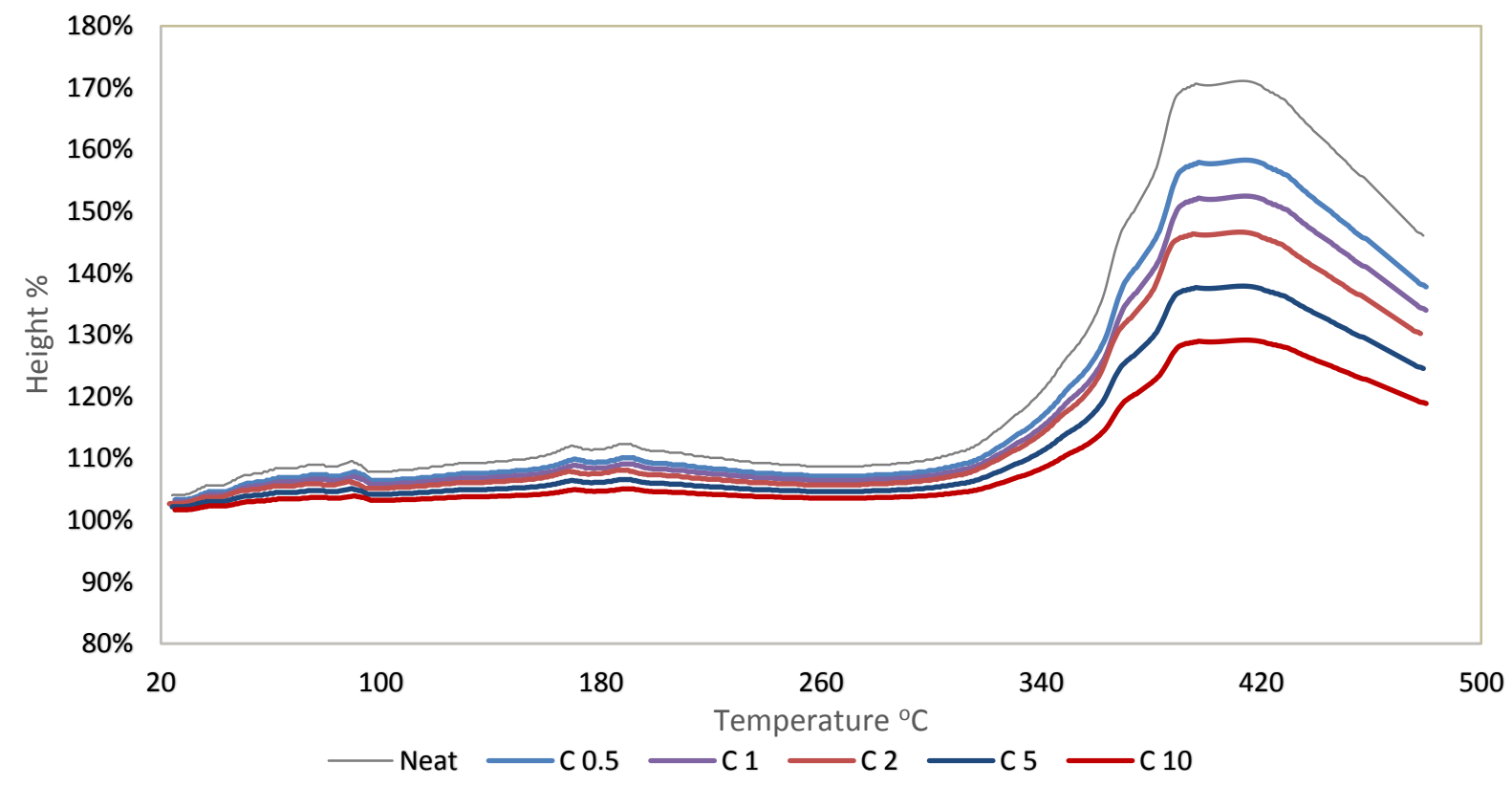

Figure 4 TMA graphs of the tested samples. 


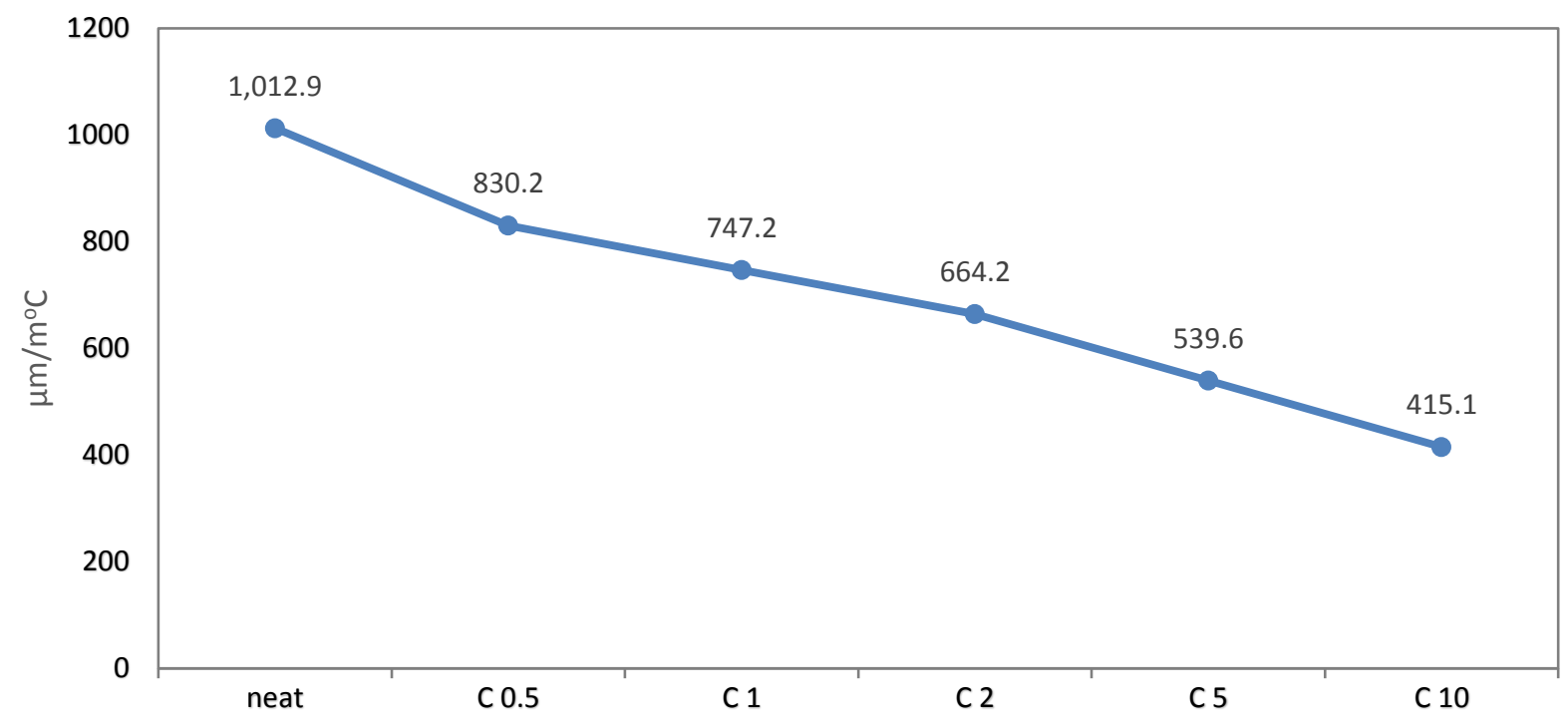

Figure 5 Thermal expansion coefficient of the tested samples.

\section{c. DSC}

Differential scanning calorimetry shows in Fig. 6 increasing in thermal stability by increasing the $\mathrm{CB}$ content and a high peak value at $350{ }^{\circ} \mathrm{C}$.

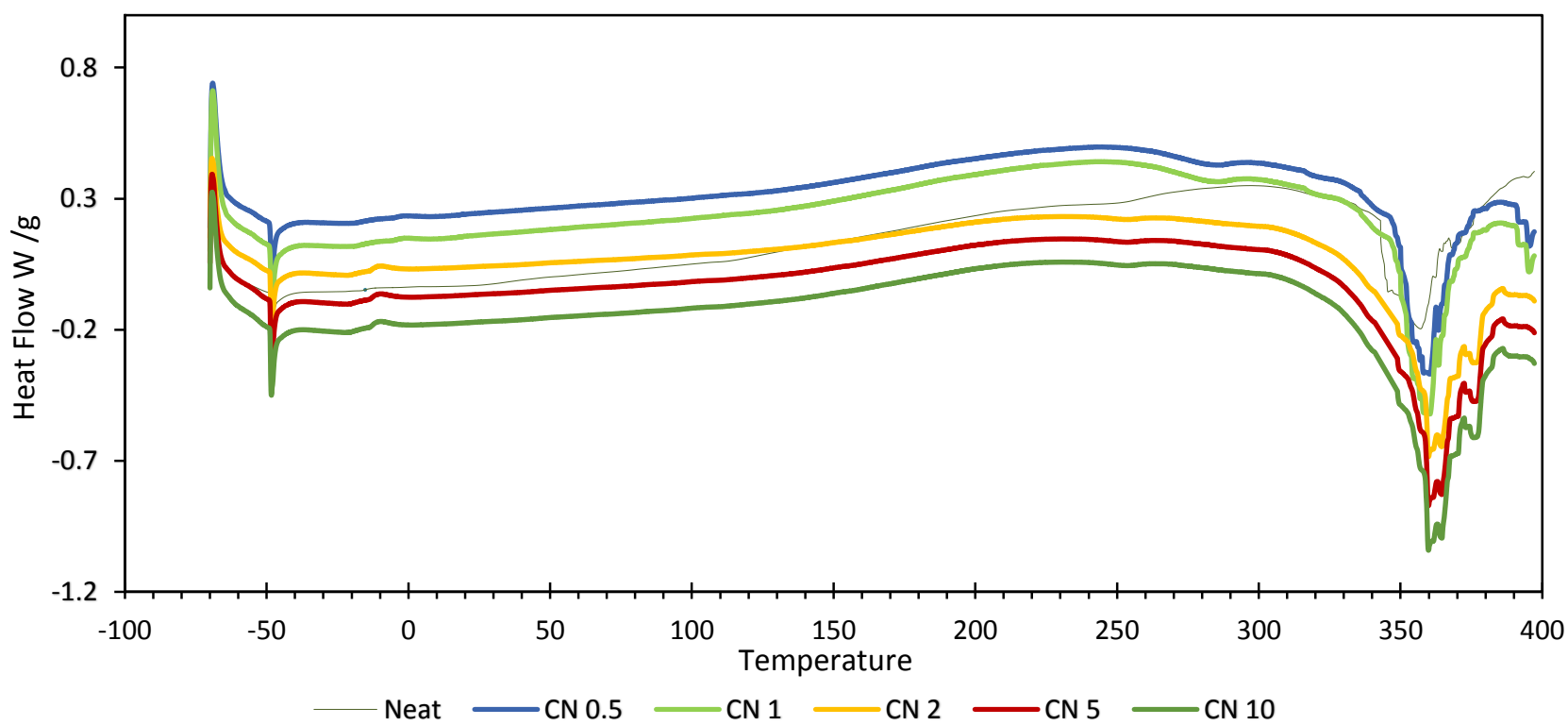

Figure 6 DSC graphs of the tested samples.

\section{d. Mechanical \& Physical Properties}

Mechanical and physical properties have been tested and reported in table 4. increasing the carbon black percentage increase the density of matrix indeed, but the density of sampled still in an acceptable limit $\left(<2 \mathrm{~g} / \mathrm{cm}^{3}\right)$. REX 1600 shore A hardness was used to perform the hardness test. The hardness was observed to be increased by raising the carbon black content, as result by increasing the hardness the resilience decreased. The introduction of $\mathrm{CB}$ to the samples leads to increase in the tensile strength and hardness. An increase in elongation at break of the samples appears by increasing $\mathrm{CB}$ percentage. The improvement in $\mathrm{C} 10$ 
elongation was decreased with increasing $\mathrm{CB}$ ratio, as result of decreasing the chain length of the matrix due to high loads of total amount of fillers.

Table 4 Mechanical and physical properties of tested sample

\begin{tabular}{l|cccccc} 
Property & Neat & C 0.5 & C 1 & C 2 & C 5 & C 10 \\
\hline Density (g/cm $\mathbf{c m}^{\mathbf{3}}$ & 1.8 & 1.8 & 1.81 & 1.83 & 1.852 & 1.88 \\
Hardness (shore) & 61 & 63 & 66 & 70 & 73 & 75 \\
Resilience & $42.8 \%$ & $42.7 \%$ & $42.5 \%$ & $42.1 \%$ & $41.2 \%$ & $40.8 \%$ \\
Tensile (MPa) & 2.8 & 2.95 & 3.15 & 3.32 & 3.712 & 3.81 \\
Elongation & $16.0 \%$ & $17.5 \%$ & $19.1 \%$ & $24.2 \%$ & $25.5 \%$ & $19.5 \%$
\end{tabular}

\section{e. Oxy-Acetylene Torch Test Results}

Ablation testing of the elastomeric ablative samples was carried out according to ASTM 28508 in which, an oxy-acetylene torch is exposed on the surface of the tested sample. The Ktype thermocouple ( $1 \mathrm{~mm}$ diameter) connected at the back-face central region of the testing specimen with the help of thermal cement; a data logger TECPEL 319 and data acquisition system are connected to measure and record the back-face temperature during the test.

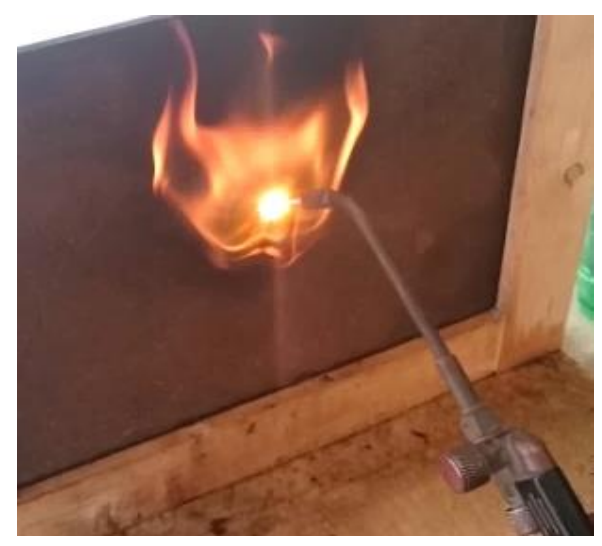

Figure 7 Sample during ablation test
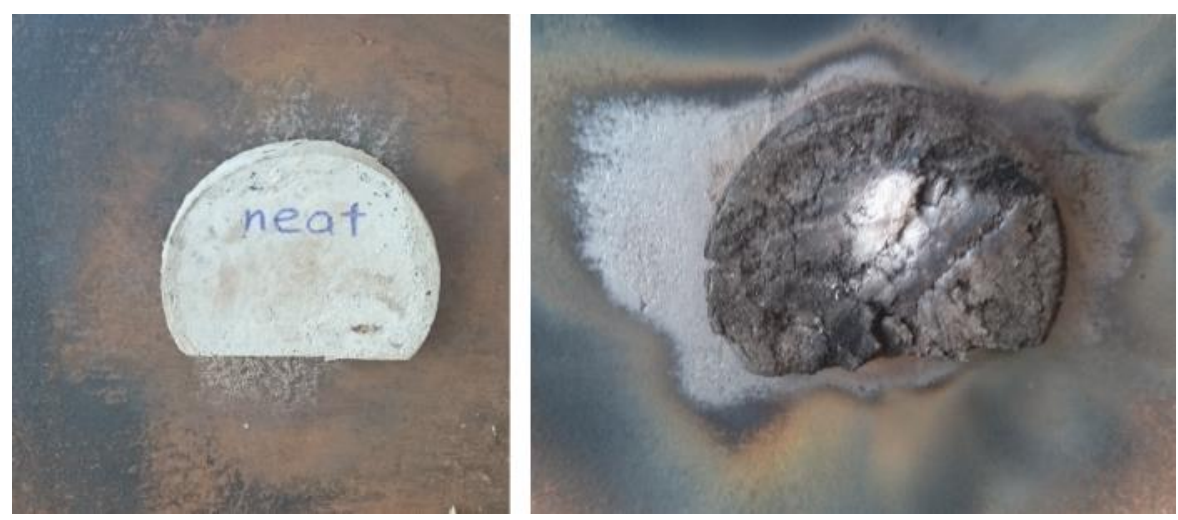

Figure 8 Neat sample before and after Oxy-acetylene torch test 


\section{In depth temperature profiles}

After 15 seconds the significant increase in the temperature profiles are observed. By increasing CB content, the temperature rises more rapidly.

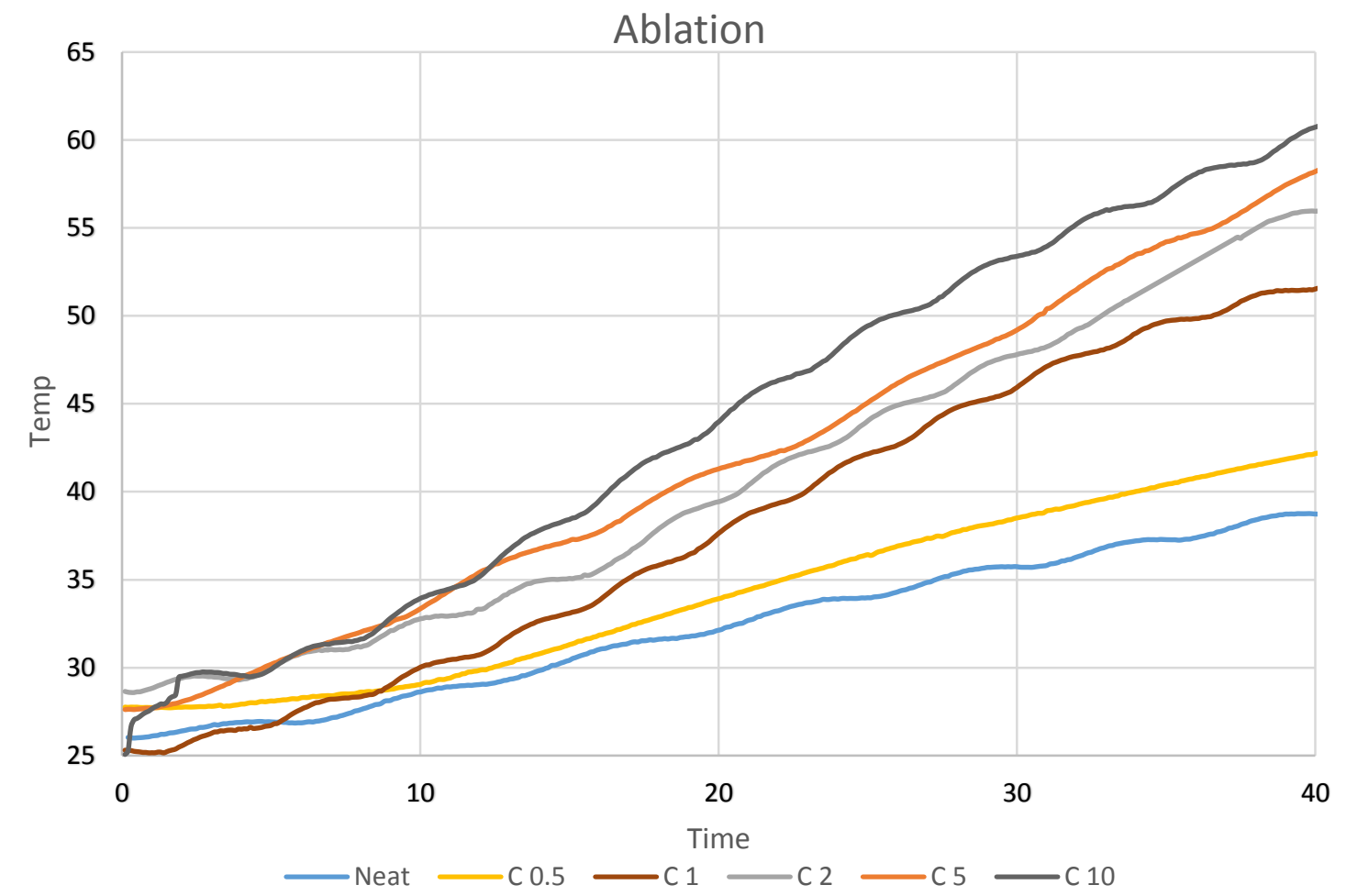

Figure 9 Temperature profile curves of samples

Table 5 Temperature of the back-face region at different duration

\begin{tabular}{l|llllll}
\multirow{2}{*}{ Time } & \multicolumn{7}{|c}{ Feedback temperature ${ }^{\circ} \mathrm{C}$} \\
& Neat & C 0.5 & C 1 & C 2 & C 5 & C 10 \\
\hline AT 15 (sec) & 30.5 & 31.3 & 33.1 & 35.1 & 37.2 & 38.4 \\
At 20 (Sec) & 32.2 & 33.9 & 37.6 & 39.4 & 41.3 & 44.0 \\
At 25 (Sec) & 34.0 & 36.4 & 42.2 & 44.0 & 45.1 & 49.4 \\
At 30 (Sec) & 35.7 & 38.5 & 45.9 & 47.8 & 49.2 & 53.4 \\
At 35 (Sec) & 37.3 & 40.4 & 49.7 & 52.7 & 54.2 & 57.0 \\
At 40 (Sec) & 38.7 & 42.2 & 51.5 & 55.8 & 58.2 & 60.7
\end{tabular}

\section{Loss of weight}

It is obvious that by increasing the carbon content the weight loss improved. This improvement due to the char layer formed by carbon content and the fire retardants. However, the improvement in weight loss percentage is insignificant.

Table 6

\begin{tabular}{|c|c|c|c|c|c|c|c|c|c|c|c|c|}
\hline Sample & \multicolumn{2}{|c|}{ Neat } & \multicolumn{2}{|c|}{ C 0.5} & \multicolumn{2}{|c|}{ C 1} & \multicolumn{2}{|c|}{ C 2} & \multicolumn{2}{|c|}{ C 5} & \multicolumn{2}{|c|}{ C 10} \\
\hline \multirow{2}{*}{ Weight } & $\begin{array}{c}\text { Befor } \\
\text { e }\end{array}$ & $\begin{array}{c}\text { Afte } \\
r\end{array}$ & $\begin{array}{c}\text { Befor } \\
\text { e }\end{array}$ & $\begin{array}{c}\text { Afte } \\
r\end{array}$ & $\begin{array}{c}\text { Befor } \\
\text { e }\end{array}$ & $\begin{array}{c}\text { Afte } \\
r\end{array}$ & $\begin{array}{c}\text { Befor } \\
\text { e }\end{array}$ & $\begin{array}{c}\text { Afte } \\
r\end{array}$ & $\begin{array}{c}\text { Befor } \\
\text { e }\end{array}$ & $\begin{array}{c}\text { Afte } \\
r\end{array}$ & Before & $\begin{array}{c}\text { Afte } \\
r\end{array}$ \\
\hline & & $\begin{array}{c}11.2 \\
1\end{array}$ & 12.23 & $\begin{array}{c}11.2 \\
1\end{array}$ & 12.5 & $\begin{array}{c}11.5 \\
3\end{array}$ & $\begin{array}{c}12.13 \\
3\end{array}$ & $\begin{array}{c}11.2 \\
5\end{array}$ & 13.18 & $\begin{array}{c}12.3 \\
2\end{array}$ & 12.3 & $\begin{array}{c}11.5 \\
1\end{array}$ \\
\hline $\begin{array}{l}\text { Weight } \\
\text { Loss \% }\end{array}$ & \multicolumn{2}{|c|}{$8.86 \%$} & \multicolumn{2}{|c|}{$8.34 \%$} & \multicolumn{2}{|c|}{$7.76 \%$} & \multicolumn{2}{|c|}{$7.27 \%$} & \multicolumn{2}{|c|}{$6.51 \%$} & \multicolumn{2}{|c|}{$6.39 \%$} \\
\hline
\end{tabular}




\section{Conclusions}

In this work, the effect of carbon black content on the properties of a selected EPDM based insulating formulation has been investigated.

- The tensile strength of C10 specimen was improved by $40 \%$. Hardness improved by $23 \%$. Elongation has been improved by $23 \%$.

- The thermal stability also has been slightly improved. The residue formation of $\mathrm{C} 10$ decreased by $50 \%$ from neat specimen. However, the thermal stability slightly increased.

- Thermal expansion coefficient decreased from $1012 \mu \mathrm{m} / \mathrm{m}^{\circ} \mathrm{C}$ of neat sample to 415 $\mu \mathrm{m} / \mathrm{m}^{\circ} \mathrm{C}$ of $\mathrm{C} 10$ sample, which is excellent improvement of thermo-mechanical properties.

- For oxy-acetylene torch, test the back-face temperature of the samples increase but within the acceptable range. The ablation resistance has been considerably improved. The weight loss from sample containing $10 \mathrm{phr}$ decreased by $28 \%$ relative to the neat specimen.

- The overall conclusion can be briefed as: the carbon black increases the mechanical and thermal properties and improve the ablative resistance properties of EPDM-based elastomers.

\section{References}

[1] A. Fathy and S. V. Hoa, Thermal insulation by heat resistant polymers for solid rocket motor insulation, vol. 46, no. 13. 2012.

[2] Mark Graham, L. Levi, and B. Clarke, "Durable Motor Insulation," 5821284, 1998.

[3] SuaeChen Chang, "Rocket motor insulation using phosphonitrilic elastomeric compositions," US5024860 A, Jun-1991.

[4] J. L. White and K.-J. Kim, Thermoplastic and Rubber Compounds. 2008.

[5] R.J. Young and P. A. Lovell, "Introduction to Polymers," SPRINGER-SCIENCE Bus. MEDIA, vol. 53, p. 443, 1989.

[6] A. AWAGON, "Introduction to Rubber Elasticity.," Nippon GOMU KYOKAISHI, vol. 69, no. 3, pp. 180-192, 1996.

[7] J. Park and K.-G. Yoon, "Thermal and Mechanical Properties of Epoxy / Micro- and Nano- Mixed Silica Composites for Insulation Materials of Heavy Electric Equipment," vol. 12, no. 3, pp. 98-101, 2011.

[8] P. Sanoj and B. Kandasubramanian, "Hybrid Carbon-Carbon Ablative Composites for Thermal Protection in Aerospace," J. Compos., vol. 2014, pp. 1-15, 2014.

[9] H. Ebadi-Dehaghani and M. Nazempour, "Thermal conductivity of nanoparticles filled polymers," Smart Nanoparticles Technol., pp. 519-534, 2012.

[10] J. Xiong, Z. Zheng, X. Qin, M. Li, H. Li, and X. Wang, "The thermal and mechanical properties of a polyurethane/multi-walled carbon nanotube composite," Carbon N. Y., vol. 44, no. 13, pp. 2701-2707, 2006.

[11] S. Singh and P. Guchhait, "EPDM Nanocomposites using Polyimide as Ablator: Morphology and Thermophysical Properties," Am. J. ..., vol. 1, no. 1, pp. 1-16, 2014.

[12] K. Deloach, "Performance of Reinforced Polymer Ablators," 2003.

[13] Y. Zheng, K. Chonung, G. Wang, P. Wei, and P. Jiang, "Epoxy / Nano-Silica Composites: Curing Kinetics, Glass Transition Temperatures, Dielectric , and Thermal - Mechanical Performances," J. Appl. Polym. Sci., vol. 21, no. 7, p. NA-NA, 2008. 
[14] Liles G. Herring, "Elastomer Insulation Compositions for Rocket Motors," pp. 4-7, 1985.

[15] J. Fan and W. Ho, "Rocket motor insulation containing coated hydrophilic fillers," Mar-2005.

[16] M. Natali, M. Monti, D. Puglia, J. M. Kenny, and L. Torre, "Ablative properties of carbon black and MWNT/phenolic composites: A comparative study," Compos. Part A Appl. Sci. Manuf., vol. 43, no. 1, pp. 174-182, 2012.

[17] G. Tang, Y. Hu, and L. Song, "Study on the flammability and thermal degradation of a novel intumescent flame retardant EPDM composite," Procedia Eng., vol. 62, pp. 371376, 2013.

[18] K. S. Ghase, S. M. El-Marsafy, E. F. Abadeer, and A. M. Samir, "Thermal and mechanical characteristics of EPDM composites," Aust. J. Basic Appl. Sci., vol. 6, no. 5, pp. 23-30, 2012.

[19] M. Natali, M. Rallini, D. Puglia, J. Kenny, and L. Torre, "EPDM based heat shielding materials for Solid Rocket Motors: A comparative study of different fi brous reinforcements," Polym. Degrad. Stab., vol. 98, no. 11, pp. 2131-2139, 2013.

[20] T. Farajpour, Y. Bayat, M. Abdollahi, and M. H. Keshavarz, "Effect of borax on the thermal and mechanical properties of ethylene-propylene-diene terpolymer rubberbased heat insulator," J. Appl. Polym. Sci., vol. 132, no. 19, pp. 1-10, 2015.

[21] M. Akiba, "Vulcanization and crosslinking in elastomers," Prog. Polym. Sci., vol. 22, no. 3, pp. 475-521, 1997.

[22] E. ASTM, "285-80. Standard test method for oxyacetylene ablation testing of thermal insulation materials," Апnи. B. ASTM Stand., vol. 15, no. 3, 2008.

[23] M. Natali, I. Puri, M. Rallini, J. Kenny, and L. Torre, "Ablation modeling of state of the art EPDM based elastomeric heat shielding materials for solid rocket motors," Comput. Mater. Sci., vol. 111, pp. 460-480, 2016.

[24] N. R. Choudhury, P. P. De, and N. K. Dutta, Thermal Analysis of Rubbers and Rubbery Materials, vol. 29, no. 8. ISmithers, 2010, page 113. 